\title{
Nodal skip metastasis in thoracic esophageal squamous cell carcinoma: a cohort study
}

\author{
Francesco Cavallin ${ }^{1 *}$, Rita Alfieri ${ }^{1}$, Marco Scarpa ${ }^{1}$, Matteo Cagol ${ }^{1}$, Alberto Ruol${ }^{2}$, Matteo Fassan $^{3}$, Massimo Rugge $^{3}$, \\ Ermanno Ancona ${ }^{1}$ and Carlo Castoro ${ }^{1}$
}

\begin{abstract}
Background: Nodal skip metastasis is a prognostic factor in some sites of malignancies, but its role in esophageal cancer is still unclear. The present study aimed to investigate occurrence and effect of nodal skip metastases in thoracic esophageal squamous cell carcinoma.

Methods: All 578 patients undergoing esophagectomy for thoracic esophageal squamous cell carcinoma at the Center for Esophageal Diseases located in Padova between January 1992 and December 2010 were retrospectively evaluated. Selection criteria were RO resection, pathological MO stage and pathological lymph node involvement. Patients receiving neoadjuvant therapy were excluded.

Results: The selection identified 88 patients with lymph node involvement confirmed by pathological evaluation. Sixteen patients (18.2\%) had nodal skip metastasis. Adjusting for the number of lymph node metastases, patient with nodal skip metastasis had similar 5 -year overall survival (14\% vs. $13 \%, p=0.93)$ and 5 -year disease free survival ( $14 \%$ vs. $9 \%, p=0.48)$ compared to patients with both peritumoral and distant lymph node metastases. The risk difference of nodal skip metastasis was: $-24.1 \%$ (95\% C.I. $-43.1 \%$ to $-5.2 \%)$ in patients with more than one lymph node metastasis compared to those with one lymph node metastasis; $-2.3 \%$ (95\% C.I. $-29.8 \%$ to $25.2 \%$ ) in middle thoracic esophagus and $-23.0 \%$ (95\% C.I. $-47.8 \%$ to $1.8 \%$ ) in lower thoracic esophagus compared to upper thoracic esophagus; $18.1 \%$ (95\% C.I. 3.2\% to 33.0\%) in clinical N0 stage vs. clinical N+ stage.

Conclusions: Nodal skip metastasis is a common pattern of metastatic lymph involvement in thoracic esophageal squamous cell carcinoma. However, neither overall survival nor disease free survival are associated with nodal skip metastasis occurrence.
\end{abstract}

Keywords: Esophageal cancer, Nodal skip metastasis, Metastasis, Lymph node involvement, Esophagectomy

\section{Background}

Esophageal cancer is a very aggressive malignancy, with poor prognosis in resected patients. Although the incidence of esophageal adenocarcinoma (EAC) has been increasing in Western Countries [1], esophageal squamous cell carcinoma (ESCC) is still the predominant esophageal malignancy in Eastern Countries, like Japan and China [2, 3].

The most important factor affecting the prognosis of ESCC patients is lymph node (LN) involvement, which

\footnotetext{
* Correspondence: cescocava@libero.it

${ }^{1}$ Esophageal and Digestive Tract Surgical Unit, Regional Centre for Esophageal Disease, Veneto Institute of Oncology IOV IRCCS, Padova, Italy Full list of author information is available at the end of the article
}

is included in the American Joint Committee of Cancer (AJCC) TNM classification [4]. The role of lymph node metastases (LNMs) on prognosis has been widely investigated, from the simple involvement to the number of involved nodes [5-7]. The ratio of LNMs on harvested nodes has also been evaluated to take into account the variability of lymph node dissection, but its role is still unclear [8]. The 7th edition of the AJCC staging system took into account all these results on $\mathrm{LN}$ involvement and it increased the classes of $\mathrm{N}$-stage according to the number of LNMs [4]. Apart from the number, the localization of LNMs could also play a role in ESCC prognosis. Since the esophagus is an organ that passes 
through three main anatomic regions (neck, chest, abdomen), the prognosis of patients with the same number of positive LNs might be different due to localization of LNMs in one or more anatomic regions [9].

Nodal skip metastasis (NSM) is a particular pattern of LNMs, which involves the LNs distant from the tumor site but not the peritumoral LNs. This pattern has been evaluated to be relevant in other kinds of malignancies $[10,11]$ but its role in esophageal cancer patients is still controversial [12]. The aim of this study was to investigate the factors predicting NSM and to assess its effect on survival and recurrence in thoracic ESCC.

\section{Methods}

\section{Study design}

The present study aimed to investigate the factors predicting NSM and to assess its effect on survival and recurrence in thoracic ESCC. All 578 patients undergoing esophagectomy for thoracic ESCC at the Center for Esophageal Diseases located in Padova between January 1, 1992 and December 31, 2010 were retrospectively evaluated for inclusion in this study using a prospectively collected database. Inclusion criteria were pathological lymph node involvement, R0 resection and absence of distant metastasis (M0) on final specimen. Patients receiving neoadjuvant therapy were excluded according to literature [12] because neoadjuvant therapy modifies frequency and distribution of LNMs [13]. Patients included in the study did not receive neoadjuvant therapy due to clinical NO stage, contraindications to chemo-radio therapy (i.e. previous radio therapy or hematopoietic comorbidities) or patient's refusal. The study was conducted according to Helsinki Declaration principles of 1975, as revised in 1983, and patients gave their consent to have their data collected for scientific purposes. This retrospective study was notified to the Ethical Committee of Veneto Oncology Institute IOV IRCCS who did not find any ethical problems (2014-06-16-Note4).

\section{Preoperative evaluation}

In all patients, preoperative evaluation was performed, including barium tests; esophageal endoscopy; computed tomography (CT) of the neck, chest, and abdomen; and bronchoscopy. Endosonography (EUS) of the esophagus and positron emission tomography scan have been part of routine esophageal cancer staging since 2000 and 2005 , respectively. Indication for surgery was determined by an experienced multidisciplinary team composed of a dedicated upper gastrointestinal surgeon, a medical oncologist and radiation oncologist.

\section{Pathology}

Histopathological examination of all resected specimens consisted in evaluation of: tumor stage, residual tumor, grading, and number of lymph nodes involved. The specimens were fixed in 5\% formaldehyde and set in paraffin. The lymph nodes were counted and assessed by a pathologist. A series of sections from each node were selected and stained with hematoxylin and eosin (H\&E) as well as with periodic acid-Schiff (PAS). All dissected lymph nodes were microscopically analyzed for metastatic disease [13].

\section{Tumor location and lymph node classification}

The seventh edition of AJCC cancer staging system was used to determine TNM stage and to classify thoracic ESCC in upper, middle and lower thoracic esophagus [4]. LNMs were assigned to five groups [12]. Laterocervical and supraclavicular nodes were assigned to cervical group. Upper and lower paratracheal nodes and upper paraesophageal nodes were assigned to upper mediastinal group, while middle paraesophageal and subcarinal nodes to middle mediastinal group, and lower paraesophageal and inferior pulmonary vein nodes to lower mediastinal group. Paracardial, perigastric and celiac nodes were assigned to abdominal group [4]. LNMs were then classified as peritumoral or distant according to the location of the tumor (Fig. 1). NSM was defined as presence of distant LNMs without presence of peritumoral LNMs. Patients with peritumoral LNMs (with or without presence of distant LNMs) were included in non-NSM group.

\section{Surgery and post-surgical follow up}

The surgical treatment consisted in open radical transthoracic esophagectomy with cervical or mediastinal anastomosis. Briefly, esophagectomy was performed using an Ivor-Lewis procedure, via laparotomy and right thoracotomy, for tumors of the mid-lower esophagus and gastric cardia. A three-stage McKeown's procedure, with an additional left cervical incision, was performed in tumors in the upper third of the esophagus. At least $6-8 \mathrm{~cm}$ of healthy esophagus was resected above the proximal edge of the tumor to avoid neoplastic involvement of the resection margins. In this group of patients, en bloc lymph node dissection was performed, including the paraesophageal, sub carinal, posterior mediastinal and paracardial lymph nodes, as well as those located along the lesser gastric curvature, the origin of the left gastric artery, the celiac trunk, the common hepatic artery and the splenic artery. Cervical nodal dissection (three-field dissection) was performed in case of suspected LNMs at preoperative evaluation. The alimentary tract was reconstructed using the gastric pull-up technique; if the stomach was unavailable, either a jejunal loop or the left colon was used. Follow-up visits were scheduled every 3 months in the first year after surgery, every 6 months during the next 2 years and every 12 months thereafter. An upper gastrointestinal endoscopy was performed regularly 1 year after surgery, or earlier based on the clinical findings, with 


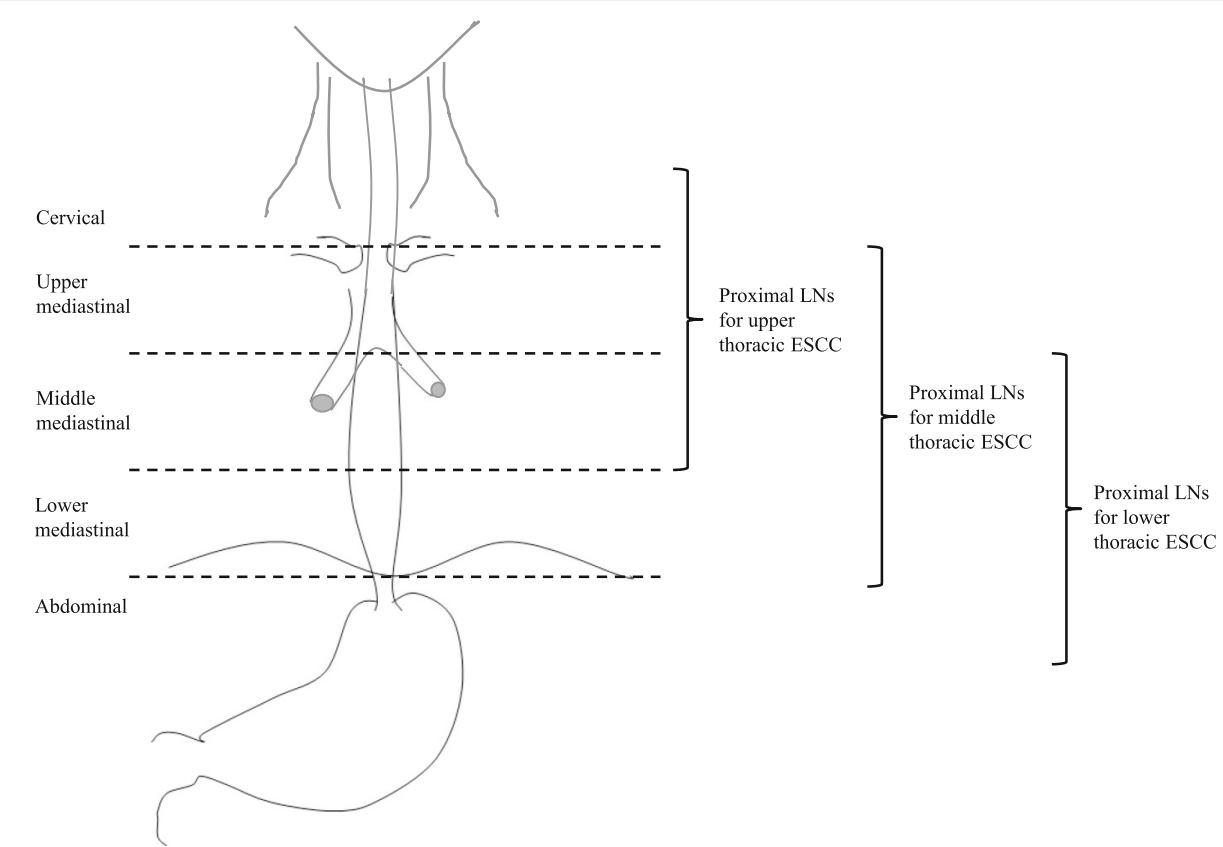

Fig. 1 Classification of lymph nodes according to tumor location. LN: Iymph node. ESCC: esophageal squamous cell carcinoma

direct evaluation of the remaining esophagus, anastomosis and of the esophageal replacement conduct. Functional results were assessed based on clinical and endoscopical findings.

\section{Statistical analysis}

Continuous data were expressed as median and interquartile range (IQR). Categorical data were compared between patients with NSM and those without NSM using Fisher's exact test and continuous data using Mann-Whitney test. Multivariable analysis of risk factors for NSM was not performed due to the small number of patient with NSM. Overall survival (OS) and disease-free survival (DFS) estimates were calculated for patients with NSM and those without NSM using Cox regression models, adjusting for the number of LNM. In addition, we reviewed the short-term follow-up of pNO patients, who were excluded from the main analysis. The occurrence of LNM at cervical, mediastinal or abdominal LNs within 6 months from surgery identified the patients who were wrongly considered pNO due to 2-field lymphadenectomy and might have been benefit from a complete lymphadenectomy. All tests were two-sided and a $p$-value less than 0.05 was considered significant. Statistical analysis was performed using SAS 9.1 (SAS Institute Inc., Cary, NC, USA).

\section{Results}

Patients

Eighty-eight patients were included in the final sample according to selection criteria (Fig. 2). These 88 patients did not receive neoadjuvant therapy due to clinical N0 stage (50 patients), contraindications to chemo-radio therapy (12 patients) or patient's refusal (26 patients). The majority were males $(71,80.7 \%)$ and the median age was 62 years (IQR 57-70). The median harvested lymph nodes was 17 (IQR 12-25). Patient characteristics are shown in Table 1.

\section{Nodal skip metastasis}

Sixteen patients (18.2\%) showed NSM and 72 (81.8\%) had both peritumoral and distant LNMs. The number of harvested lymph nodes was similar in the two groups (median 18 in NSM vs. 17 in non-NSM patients, $p=0.72$; Table 2), but patients with NSM had lower number of metastatic lymph nodes than those without NSM (median 1 vs. 2, $p=0.01$; Table 2). The risk difference of NSM was $-24.1 \%$ (95\% C.I. $-43.1 \%$ to $-5.2 \%$ ) in patients with more than one LNM compared to those with one LNM. The rate of NSM was different according to tumor location $(p=0.02$; Table 2$)$ and clinical $\mathrm{N}$ stage $(p=0.04$; Table 2). Compared to upper thoracic esophagus, the risk difference of NSM was $-2.3 \%$ (95\% C.I. $-29.8 \%$ to $25.2 \%$ ) in middle thoracic esophagus and $-23.0 \%$ (95\% C.I. $-47.8 \%$ to $1.8 \%$ ) in lower thoracic esophagus. The risk difference of NSM was $18.1 \%$ (95\% C.I. $3.2 \%$ to $33.0 \%$ ) in clinical N0 stage vs. clinical N+ stage.

\section{Survival}

Median follow-up was 23 months (IQR 14-41). Three patients died of postoperative complications (two cardiopulmonary and one sepsis). The 5-year OS was similar 
578 pts underwent esophagectomy for thoracic ESCC during 1992-2010

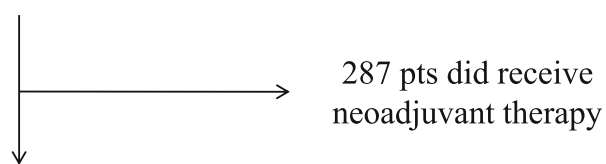

291 pts did not receive neoadjuvant therapy

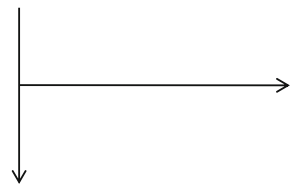

32 pts R1-2 resection

259 pts $\mathrm{R} 0$ resection

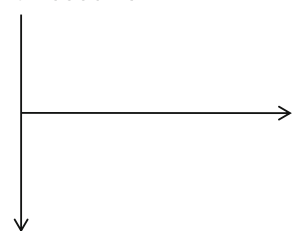

230 pts pM0

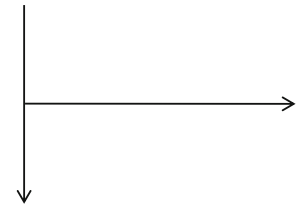

142 pts pN0

$88 \mathrm{pts} \mathrm{pN}+$ included in the analysis

Fig. 2 Flow chart of patient inclusion

in patients with NSM and in those without NSM (14\% vs. $13 \%$ respectively; $p=0.93$; Fig. 3a), adjusting for the number of LNM. The 5-year DFS was similar in patients with NSM and in those without NSM (14\% vs. $9 \%$ respectively; $p=0.48$; Fig. $2 \mathrm{~b}$ ), adjusting for the number of LNM.

\section{Recurrence pattern in NSM patients}

Recurrence was detected in 10 out of 16 NSM patients. One patient had upper esophageal ESCC with abdominal NSM and the recurrence site was locoregional. One patient had upper esophageal ESCC with abdominal NSM and the recurrence site was both locoregional and distant (pulmonary LN). Four patients had middle esophageal ESCC with abdominal lymph node involvement and the recurrence site was locoregional. Three patients had middle esophageal ESCC with abdominal lymph node involvement and the recurrence site was distant. One patient had middle esophageal ESCC with abdominal lymph node involvement and the recurrence site was both locoregional and distant (pulmonary LN and abdominal LN).
Table 1 Clinical and pathological characteristics

\begin{tabular}{|c|c|}
\hline Number & 88 \\
\hline Age (years) ${ }^{a}$ & $62(57-70)$ \\
\hline Sex Male: Female & $71: 17$ \\
\hline Advanced liver disease & $18(20.5)$ \\
\hline Pulmonary disease & $17(19.3)$ \\
\hline \multicolumn{2}{|l|}{ Tumor location: } \\
\hline Upper thoracic esophagus & $14(15.9)$ \\
\hline Middle thoracic esophagus & $38(43.2)$ \\
\hline Lower thoracic esophagus & $36(40.9)$ \\
\hline \multicolumn{2}{|l|}{ Tumor differentiation: } \\
\hline Well & $16(18.2)$ \\
\hline Moderately & $57(64.8)$ \\
\hline Poor & $15(17.0)$ \\
\hline Tumor length $(\mathrm{mm})^{\mathrm{a}}$ & $50(40-70)$ \\
\hline \multicolumn{2}{|l|}{ Pathologic T stage } \\
\hline T1 & $11(12.5)$ \\
\hline $\mathrm{T} 2$ & $10(11.4)$ \\
\hline T3 & $58(65.9)$ \\
\hline T4 & $9(10.2)$ \\
\hline Harvested lymph nodes ${ }^{a}$ & $17(12-25)$ \\
\hline \multicolumn{2}{|l|}{ Lymph node metastasis: } \\
\hline Peritumoral or Peritumoral and distant (non-NSM) & $72(81.8)$ \\
\hline Only distant (NSM) & $16(18.2)$ \\
\hline Adjuvant therapy: yes & $28(31.8)$ \\
\hline
\end{tabular}

Data expressed as $\mathrm{n}(\%)$ or ${ }^{\mathrm{a}}$ median(IQR). NSM: nodal skip metastasis

\section{Sub-analysis of pNO patients}

Among the 142 pN0 patients who were excluded from the main analysis (Fig. 1), 3 patients (2.1\%) had LNM at cervical, mediastinal or abdominal LNs within 6 months from surgery. One patient out of 41 (2.4\%) with upper thoracic ESCC had a cervical LNM (i.e. would have been included in the non-NSM group) and died after CTRT treatment at 10 months from surgery. Two patients out of 67 (3\%) with middle thoracic ESCC had a cervical LNM (i.e. would have been included in the NSM group) and died after palliative resection and CTRT at 13 and 19 months, respectively. None of pN0 patients with lower thoracic ESCC had LNM at cervical, mediastinal or abdominal LNs within 6 months from surgery. Adding these 3 patients to the 88 patients of the main analysis, the rate of NSM would have increased from $18.2 \%$ (16 out of 88 ) to $19.8 \%$ (18 out of 91 ).

\section{Discussion}

NSM is not an uncommon form of metastatic spread to lymph nodes and has been found to be of clinical importance in some sites of malignancies, i.e. non-small cell lung cancer or thyroid cancer $[10,11]$. The presence 
Table 2 Factors associated with nodal skip metastasis

\begin{tabular}{|c|c|c|c|}
\hline & Non-NSM & NSM & $p$-value \\
\hline Number & 72 & 16 & - \\
\hline Age (years) ${ }^{a}$ & $63(57-70)$ & $59(54-69)$ & 0.64 \\
\hline Sex Male: Female & $59: 13$ & $12: 4$ & 0.50 \\
\hline Advanced liver disease & $15(20.8)$ & $3(18.8)$ & 0.99 \\
\hline Pulmonary disease & $14(19.4)$ & $3(18.8)$ & 0.99 \\
\hline Tumor location: & & & 0.02 \\
\hline Upper thoracic esophagus & $10(13.9)$ & $4(25.0)$ & \\
\hline Middle thoracic esophagus & $28(38.9)$ & $10(62.5)$ & \\
\hline Lower thoracic esophagus & $34(47.2)$ & $2(12.5)$ & \\
\hline Tumor differentiation: & & & 0.21 \\
\hline Well & $11(15.3)$ & $5(31.3)$ & \\
\hline Moderate & $47(65.3)$ & $10(62.5)$ & \\
\hline Poor & $14(19.4)$ & $1(6.2)$ & \\
\hline Tumor length $(\mathrm{mm})^{\mathrm{a}}$ & $50(40-70)$ & $50(35-50)$ & 0.22 \\
\hline Preoperative clinical N stage: & & & 0.04 \\
\hline $\mathrm{cN}+$ & $35(48.6)$ & $3(18.8)$ & \\
\hline cNO & $37(51.4)$ & $13(81.2)$ & \\
\hline Pathologic T stage: & & & 0.99 \\
\hline pT1-pT2 & 17 (23.6) & $4(25.0)$ & \\
\hline pT3-pT4 & $55(76.4)$ & $12(75.0)$ & \\
\hline Harvested lymph nodes $^{\mathrm{a}}$ & $17(12-25)$ & $18(13-23)$ & 0.72 \\
\hline Metastatic lymph nodes ${ }^{a}$ & $1(1-3)$ & $2(1-5)$ & 0.01 \\
\hline
\end{tabular}

Data expressed as $\mathrm{n}(\%)$ or ${ }^{\mathrm{a}}$ median(IQR), NSM nodal skip metastasis

of NSM has also been evaluated in esophageal cancer but its prognostic role is still unclear and requires further investigation [12, 14-18]. Recent studies on this topic are summarized in Table 3 . The rate of NSM in esophageal cancer varied widely across the studies (from $20.3 \%$ to $76.3 \%$, Table 3), increasing the uncertainty about this type of metastatic spread. Such variability could be explained by the different criteria of lymph node classification criteria that were used by the authors. Briefly, NSM has been defined as a) metastatic involvement of distant LNs with peritumoral LNs free of tumor infiltration [12, 16, 18,], b) cervical and/or abdominal involvement but no mediastinal metastasis $[14,15,19]$, or c) metastatic infiltration of $\mathrm{N} 2$ through $\mathrm{N} 4$ lymph nodes but not of N1 nodes according to the Japanese staging system of the Japanese Society for Esophageal Disease $[15,17]$. The first definition (metastatic involvement of distant LNs with peritumoral LNs free of tumor infiltration) was used in the present study because we believed it would afford a stricter definition of skip lymph nodes. It is noteworthy that $\mathrm{Wu}$ et al. [15] used different lymph node classification criteria to evaluate the same sample and reported very different rates of NSM $(24.2 \%$ and 69.7\%). In addition, the different node dissection (both

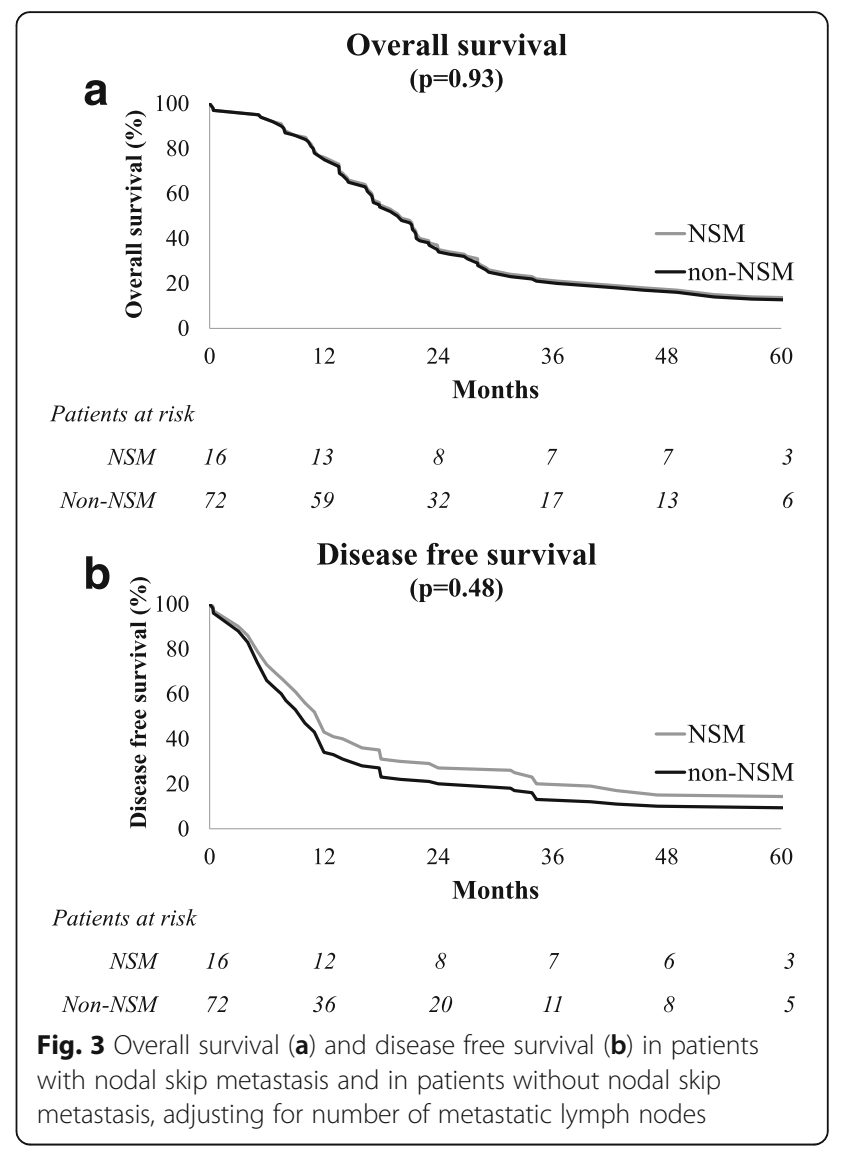

2-field and 3-field node dissections have been reported) [19] and the inclusion of both EAC and ESCC patients in 2 studies could have contributed to the variability of the reported rate of NSM (Table 3).

Predictors of NSM in esophageal cancer has been investigated in three previous studies $[12,17,18]$ that reported tumor location as the main factor associated to NSM (Table 3). In our series, the number of NSM patients did not allow any meaningful multivariable analysis of risk factors for NSM. However, univariate analysis suggested a higher NSM occurrence in upper and middle thoracic esophagus. In literature, tumors located in the middle thoracic esophagus were identified as risk factor for NSM, despite slight differences among the studies regarding the comparison of tumor sites (Table 3). The association between NSM and middle thoracic esophageal tumors could be explained by its anatomic location (which allows both upper and lower spread directions) and by the definition itself of NSM (cervical and abdominal lymph nodes are possible NSMs), which increase the likelihood of finding NSMs in tumors located in middle thoracic esophagus [20-22].

In our series, patients with NSM showed similar overall survival and disease free survival compared to those with peritumoral LNM, adjusting for the number of 
Table 3 Main findings of recent literature: all patients had thoracic esophageal cancer and were treated with esophagectomy without neoadjuvant therapy

\begin{tabular}{|c|c|c|c|c|c|c|c|c|}
\hline $\begin{array}{l}\text { First author and } \\
\text { year }\end{array}$ & Country & Histotype & $\begin{array}{l}\text { Node } \\
\text { dissection }\end{array}$ & $\begin{array}{l}\text { N pts. with } \\
\text { LNM }\end{array}$ & NSM rate & Predictors of NSM & $\begin{array}{l}\text { Effect of } \\
\text { NSM on OS }\end{array}$ & $\begin{array}{l}\text { Effect of NSM } \\
\text { on DFS }\end{array}$ \\
\hline Zhu, $2013^{\mathrm{a}}[13]$ & China & ESCC & 3-field & 207 & $28 \%$ & $\begin{array}{l}\text { Tumor location } \\
\text { (middle esophagus) }\end{array}$ & $\begin{array}{l}\text { Similar } \\
\text { prognosis }\end{array}$ & $\begin{array}{l}\text { Not } \\
\text { evaluated }\end{array}$ \\
\hline $\mathrm{Li}, 2013^{\mathrm{b}}[14]$ & China & $\begin{array}{l}\text { Superficial } \\
\text { ESCC }\end{array}$ & 2-field/3-field & 49 & $40.8 \%$ & Not evaluated & $\begin{array}{l}\text { Not } \\
\text { evaluated }\end{array}$ & $\begin{array}{l}\text { Not } \\
\text { evaluated }\end{array}$ \\
\hline Wu, 2012 b c [15] & China & $\begin{array}{l}\text { Middle thoracic } \\
\text { ESCC }\end{array}$ & 2-field/3-field & 33 & $\begin{array}{l}24.2 \% \text { to } \\
69.7 \%{ }^{d}\end{array}$ & Not evaluated & $\begin{array}{l}\text { Similar } \\
\text { prognosis }\end{array}$ & $\begin{array}{l}\text { Not } \\
\text { evaluated }\end{array}$ \\
\hline$X u, 2011^{a}[16]$ & China & ESCC & Not reported & 38 & $76.3 \%$ & Not evaluated & $\begin{array}{l}\text { Similar } \\
\text { prognosis }\end{array}$ & $\begin{array}{l}\text { Not } \\
\text { evaluated }\end{array}$ \\
\hline Prenzel, $2010^{\complement}$ [17] & Germany & EAC/ESCC & 2-field & 128 & $20.3 \%$ & $\begin{array}{l}\text { Tumor location } \\
\text { (middle/upper esophagus) } \\
\text { and T1 stage }\end{array}$ & $\begin{array}{l}\text { Better } \\
\text { prognosis }\end{array}$ & $\begin{array}{l}\text { Not } \\
\text { evaluated }\end{array}$ \\
\hline Chen, $2009^{a}[18]$ & China & ESCC & 3-field & 1081 & $73.6 \%$ & $\begin{array}{l}\text { Tumor location } \\
\text { (middle/lower esophagus) }\end{array}$ & $\begin{array}{l}\text { Not } \\
\text { evaluated }\end{array}$ & $\begin{array}{l}\text { Not } \\
\text { evaluated }\end{array}$ \\
\hline
\end{tabular}

LNM lymph node metastasis, NSM nodal skip metastasis, OS overall survival, DFS disease free survival, ESCC esophageal squamous cell carcinoma, EAC esophageal adenocarcinoma. ${ }^{a} \mathrm{NSM}$ defined as metastatic involvement of distant LNs with peritumoral LNs free of tumor infiltration. ${ }^{\mathrm{b}} \mathrm{NSM}$ defined as cervical and/or abdominal involvement but no mediastinal metastasis. ' NSM defined as metastatic infiltration of N2 through N4 lymph nodes but not of N1 nodes according to the Japanese staging system of the Japanese Society for Esophageal Disease. ${ }^{d}$ According to the different definitions evaluated in the study

LNMs. Similar findings on overall survival in ESCC patients were shown by 3 previous Chinese studies [12, 15, 16] while Prenzel et al. [17] reported a favorable prognosis associated with the presence of NSM in a heterogeneous group of both ESCC and EAC patients. It was surprising that NSM (distant metastases in absence of local metastases) did not affect overall survival. Our hypothesis is that patient immune response to cancer cells cleared the peritumoral metastases while some surviving clones proceeded to further nodal stations. Therefore, NSM might represent a final escape step of ESCC progression [23]. In addition, previous data on favorable prognosis of NSM in ESCC might have been biased by the lower number of LNMs in NSM patients. We think that these considerations might be extended to disease free survival, but the literature did not provide useful data on the association between NSM and disease free survival in ESCC.

Our series included over 50\% clinical N0 stages, thus the role of radical lymphadenectomy is further enhanced, even in case of apparent NO stage at clinical evaluation. Moreover, NSM was less likely identified than local LN involvement during preoperative evaluation (cN0 rate $81.2 \%$ vs. $51.4 \%$ ). These findings support the potential usefulness of innovative techniques such as sentinel node assessment in order to intraoperatively identify the pattern of LN involvement [24].

The present study has some limitations. First, it is a retrospective study on a single-institution series. Second, the number of patients may have prevented some findings from being extrapolated. Third, the quality of lymphadenectomy could have affected the results. However, all esophagectomies were performed by the same surgical team; - thus the warranted homogeneity of the surgical approach - and the number of harvested nodes were acceptable. In fact, 2-field lymphadenectomy failed to identify LNM in only 3 patients $(2.1 \%)$ who had cervical nodal metastasis and had been staged $\mathrm{NO}$ at pathologic evaluation upon final specimen.

\section{Conclusions}

NSM is a common pattern of metastatic LN involvement in thoracic ESCC, but it does not affect the prognosis. The heterogeneity of the studies on NSM in literature requires further evaluation in order to investigate this lymph node metastatic spread.

\section{Abbreviations}

CT: Computed tomography; DFS: Disease free survival; EAC: Esophageal adenocarcinoma; ESCC: Esophageal squamous cell carcinoma; EUS: Endosonography; IQR: Interquartile range; LN: Lymph node; LNM: Lymph node metastasis; NSM: Nodal skip metastasis; OS: Overall survival

\section{Acknowledgments}

The authors are grateful to Ms. Christina Drace (Language Revision Service, Veneto Institute of Oncology IOV IRCCS, Padova, Italy) for the English revision of the manuscript. Ms. Christina Drace is a native English speaker.

\section{Funding}

None.

\section{Availability of data and materials}

The datasets analyzed during the current study is available from the corresponding author on reasonable request.

\section{Authors' contributions}

FC, MS and CC designed the study; MC, RA, AR, MF, MR and EA collected the data; FC and MS analyzed the data; FC, MS and CC wrote the manuscript; $M C, R A, A R, M F, M R$ and EA critically revised the manuscript for important intellectual content; all authors read and approved the final manuscript.

Competing interests

The authors declare that they have no competing interests. 


\section{Consent for publication}

Not applicable.

\section{Ethics approval and consent to participate}

The study was conducted in accordance with the principles of the Declaration of Helsinki and all patients gave their consent to have their data collected for scientific purposes. This retrospective study was notified to the Ethical Committee of Veneto Oncology Institute IOV IRCCS who did not find any ethical problems (2014-06-16-Note4).

\section{Publisher's Note}

Springer Nature remains neutral with regard to jurisdictional claims in published maps and institutional affiliations.

\section{Author details}

${ }^{1}$ Esophageal and Digestive Tract Surgical Unit, Regional Centre for Esophageal Disease, Veneto Institute of Oncology IOV IRCCS, Padova, Italy. ${ }^{2} 3$ rd Surgical Clinic, Azienda Ospedaliera di Padova, Padova, Italy. ${ }^{3}$ Department of Medicine (DIMED), Surgical Pathology \& CytopathologyUnit, University of Padova, Padova, Italy.

Received: 18 February 2017 Accepted: 20 April 2017

\section{Published online: 02 May 2017}

\section{References}

1. Torre LA, Bray F, Siegel RL, Ferlay J, Lortet-Tieulent J, Jemal A. Global cancer statistics, 2012. CA Cancer J Clin. 2015;65:87-108.

2. Domper Arnal MJ, Ferrández Arenas Á, Lanas AÁ. Esophageal cancer: risk factors, screening and endoscopic treatment in western and eastern countries. World J Gastroenterol. 2015;21:7933-43.

3. Tran GD, Sun XD, Abnet CC, Fan JH, Dawsey SM, Dong ZW, Mark SD, Qiao YL, Taylor PR. Prospective study of risk factors for esophageal and gastric cancers in the Linxian general population trial cohort in China. Int J Cancer. 2005;113:456-63.

4. Edge SB, Byrd DR, Compton CC, Fritz AG, Greene FL, Trotti A. AJCC cancer staging manual. 7th ed. New York: Springer; 2009.

5. Kayani B, Zacharakis E, Ahmed K, Hanna GB. Lymph node metastases and prognosis in oesophageal carcinoma - a systematic review. Eur I Surg Oncol. 2011;37:747-53.

6. Akutsu Y, Shuto K, Kono T, Uesato M, Hoshino I, Shiratori T, Isozaki Y, Akanuma $\mathrm{N}$, Uno T, Matsubara $\mathrm{H}$. The number of pathologic lymph nodes involved is still a significant prognostic factor even after neoadjuvant chemoradiotherapy in esophageal squamous cell carcinoma. J Surg Oncol. 2012;15(105):756-60

7. Zheng YZ, Zhao W, Hu Y, Ding-Lin XX, Wen J, Yang H, Liu QW, Luo KJ Huang QY, Chen JY, Fu JH. Aggressive surgical resection does not improve survival in operable esophageal squamous cell carcinoma with N2-3 status. World J Gastroenterol. 2015;21:8644-52.

8. Mariette C, Piessen G, Briez N, Triboulet JP. The number of metastatic lymph nodes and the ratio between metastatic and examined lymph nodes are independent prognostic factors in esophageal cancer regardless of neoadjuvant chemoradiation or lymphadenectomy extent. Ann Surg. 2008;247:365-71.

9. Zheng WH, Zhu SM, Zhao A, Mao WM. The prognostic impact of lymph node involvement in large scale operable node-positive esophageal Squamous cell carcinoma patients: a 10-year experience. PLoS One. 2015;10:e0133076.

10. Prenzel KL, Mönig SP, Sinning JM, Baldus SE, Gutschow CA, Grass G, Schneider PM, Hölscher AH. Role of skip metastasis to mediastinal lymph nodes in non-small cell lung cancer. J Surg Oncol. 2003;82:256-60.

11. Machens A, Holzhausen HJ, Dralle H. Skip metastases in thyroid cancer leaping the central lymph node compartment. Arch Surg. 2004;139:43-5.

12. Zhu Z, Yu W, Li H, Zhao K, Zhao W, Zhang Y, Sun M, Wei Q, Chen H, Xiang $\mathrm{J}$, Fu X. Nodal skip metastasis is not a predictor of survival in thoracic esophageal squamous cell carcinoma. Ann Surg Oncol. 2013;20:3052-8.

13. Castoro C, Scarpa M, Cagol M, Ruol A, Cavallin F, Alfieri R, Zanchettin G, Rugge M, Ancona E. Nodal metastasis from locally advanced esophageal cancer: how neoadjuvant therapy modifies their frequency and distribution. Ann Surg Oncol. 2011;18:3743-54.

14. Li B, Chen H, Xiang J, Zhang Y, Kong Y, Garfield DH, Li H. Prevalence of lymph node metastases in superficial esophageal squamous cell carcinoma. J Thorac Cardiovasc Surg. 2013;146:1198-203.
15. Wu J, Chen QX, Zhou XM, Mao WM, Krasna MJ, Teng LS. Prognostic significance of solitary lymph node metastasis in patients with squamous cell carcinoma of middle thoracic esophagus. World J Surg Oncol. 2012;10:210.

16. Xu QR, Zhuge XP, Zhang HL, Ping YM, Chen LQ. The N-classification for esophageal cancer staging: should it be based on number, distance, or extent of the lymph node metastasis? World J Surg. 2011;35:1303-10.

17. Prenzel KL, Bollschweiler E, Schröder W, Mönig SP, Drebber U, Vallboehmer D, Hölscher AH. Prognostic relevance of skip metastases in esophageal cancer. Ann Thorac Surg. 2010;90:1662-7.

18. Chen J, Liu S, Pan J, Zheng X, Zhu K, Zhu J, Xiao J, Ying M. The pattern and prevalence of lymphatic spread in thoracic oesophageal squamous cell carcinoma. Eur J Cardiothorac Surg. 2009;36:480-6.

19. Li H, Zhang Y, Cai H, Xiang J. Pattern of lymph node metastases in patients with squamous cell carcinoma of the thoracic esophagus who underwent three-field lymphadenectomy. Eur Surg Res. 2007;39:1-6.

20. Tachibana M, Kinugasa S, Hirahara N, Yoshimura H. Lymph node classification of esophageal squamous cell carcinoma and adenocarcinoma. Eur J Cardiothorac Surg. 2008;34:427-31.

21. Skandalakis JE, Ellis H. Embryologic and anatomic basis of esophageal surgery. Surg Clin North Am. 2000;80:85-155.

22. Hosch SB, Stoecklein NH, Pichlmeier U, Rehders A, Scheunemann P, Niendorf A, Knoefel WT, Izbicki JR. Esophageal cancer: the mode of lymphatic tumor cell spread and its prognosticsignificance. J Clin Oncol. 2001;19:1970-5.

23. Dunn GP, Bruce AT, Ikeda H, Old L, Schreiber RD. Cancer immunoediting: from immunosurveillance to tumor escape. Nat Immunol. 2002;3:991-998.

24. Filip B, Scarpa M, Cavallin F, Alfieri R, Cagol M, Castoro C. Minimally invasive surgery for esophageal cancer: a review on sentinel node concept. Surg Endosc. 2014;28:1238-49.

\section{Submit your next manuscript to BioMed Central and we will help you at every step:}

- We accept pre-submission inquiries

- Our selector tool helps you to find the most relevant journal

- We provide round the clock customer support

- Convenient online submission

- Thorough peer review

- Inclusion in PubMed and all major indexing services

- Maximum visibility for your research

Submit your manuscript at www.biomedcentral.com/submit
Biomed Central 